\section{Pengaruh Kualitas Layanan Dan Citra Merek Terhadap Loyalitas Pelanggan Melalui Kepuasan Pelanggan Pada Pelanggan Jasa Jne Di Yogyakarta}

Service Quality,

Brand Image and

Customer Loyalty to

Jne Customers

\author{
Putri Wulandari ${ }^{1}$, Heru Tri Sutiono ${ }^{2}$,Sri Kussujaniatun ${ }^{3}$ \\ Fakultas Ekonomi dan Bisnis Universitas Pembangunan Nasional "Veteran" \\ Yogyakarta \\ Email : putriwulan013@gmail.com heruts@upnyk.ac.id \\ sri_kussujaniatun@yahoo.co.id
}

\begin{abstract}
The purpose of this study is to analyze the effect of service quality and brand image on customer loyalty through customer satisfaction to customer service JNE in Yogyakarta. The method used was purposive sampling, with the sampling of the population is based on certain criteria namely JNE service customer in Yogyakarta have used JNE service at least 2 times. The sample in this study were 270 respondents. Data analysis methods include descriptive analysis and quanitative analysis using the SEM (Structural Equation Modeling), an analysis technique based on PLS (Structural Equation Modeling). The result of this study prove that (1) service quality has a positive and significant effect on customer satisfaction (2) brand image service quality has a positive and significant effect on customer satisfaction (3) service quality has a positive and significant effect on customer loyalty (4) brand image has a positive and significant effect on customer loyalty (5) customer satisfaction has a positive and significant effect on customer loyalty (6) service quality has a positive and significant effect on customer loyalty through customer satisfaction (7) brand image has a positive and significant effect on customer loyalty through customer satisfaction.
\end{abstract}

Keyword: service quality, barand image, customer satisfaction, and customer loyalty

\section{PENDAHULUAN}

Dunia bisnis saat ini banyak perubahan, karena hal itu perusahaan harus dapat mempersiapkan diri dan merespon perubahan tersebut agar perusahaan dapat bertahan dan berkembang. Sejak adanya kemajuan teknologi saat ini masyarakat cenderung menyukai sesuatu yang bersifat mudah dan praktis. Saat ini muncul bisnis online yang berkembang pesat memicu tumbuhnya jasa pengiriman barang di Indonesia. Jasa kurir JNE menjadi market leader jasa kurir di Indonesia pada tahun 2018, JNE menjadi penguasa pasar jasa kurir dengan presentase sebesar $45,5 \%$. Perusahaan jasa membangun sebuah merek (brand) merupakan salah satu hal pertimbangan utama bagi calon pengguna jasa untuk menentukan jasa pengiriman barang atau kurir yang akan dipilih. Nama perusahaan jasa pengiriman barang yang memiliki layanan terbaik dan merek yang terkenal di Indonesia salah satunya adalah PT Tiki Jalur Nugraha Ekakurir atau sering disebut JNE adalah perusahaan milik swasta yang berdiri tahun 1990. JNE menjadi top of mind di Indonesia. Pokok permasalahannya yaitu bagaimana JNE mampu mempertahankan reputasinya agar tetap menempati top brand awards pada posisi pertama dan tetap menjadi market leader. Untuk mempertahankan reputasinya dengan terus meningkatkan market sharenya. JNE harus memiliki strategi pemasarannya hendaknya memikirkan salah satunya dari segi loyalitas pelanggan. Menurut Lupiyodi (2018) loyalitas pelanggan terkait dengan kelangsungan perusahaan dan terhadap kuatnya pertumbuhan perusahaan di masa depan dengan demikian perusahaan mampu mempertahankan profit yang stabil saat kompetisi bisnis begitu tajam, strategi untuk mempertahankan pelanggan dan strategi agresif untuk memperluas pangsa pasar konsumen potensial. Menurut Kotler \& Amstrong (2001) membuat pelanggan tetap bertahan merupakan ukuran terbaik untuk kualitas atas kemampuan perusahaan dalam memepertahankan pelanggannya, tergantung pada konsistensi perusahaan menyampaikan nilai kepada pelanggan. Menurut Gerson (2004) pelanggan yang merasa puas akan sering menggunakan jasa yang pernah digunakannya lagi. Dari hasil penelitian MARET 2021

Accepted: JUNI 2021

\section{JIMKES}

Jurnal Ilmiah Manajemen Kesatuan Vol. 9 No. 2, 2021 pp. 293-308 IBI Kesatuan
ISSN $2337-7860$ E-ISSN 2721 - 169X DOI: $10.37641 /$ jimkes.v9i2.470
Submitted: 
Service Quality,

Brand Image and

Customer Loyalty to

Jne Customers

294 terdapat kesenjangan atau gap, maka diperlukan penelitian kembali pengaruh citra merek terhadap loyalitas pelanggan dengan melibatkan variabel kualitas layanan dan kepuasan pelanggan pada situasi, waktu tempat, dan objek yang berbeda. Menurut peneliti terdahulu Damyati \& Subagio, (2016) membuktikan bahwa citra merek tidak signifikan berpengaruh positif terhadap loyalitas pelanggan. Pada penelitian lain Lise \& Sitio (2019) , penelitian Nastiti \& Astuti (2019) dan penelitian Syahputra (2020) pada penelitian ini membuktikan bahwa citra merek signifikan berpengaruh positif terahadap loyalitas pelanggan.

Berdasarakan latar belakang diatas, maka perusahaan masalah dalam penelitian ini dapat dirumuskan sebagai berikut :

a. Apakah terdapat pengaruh positif kualitas layanan terhadap kepuasan pelanggan pada Pelanggan jasa JNE di Yogyakarta?

b. Apakah terdapat pengaruh positif citra merek terhadap kepuasan pelanggan pada Pelanggan jasa JNE di Yogyakarta?

c. Apakah terdapat pengaruh positif kualitas layanan terhadap loyalitas pada Pelanggan jasa JNE di Yogyakarta?

d. Apakah terdapat pengaruh positif citra merek terhadap loyalitas pada Pelanggan jasa JNE di Yogyakarta?

e. Apakah terdapat pengaruh positif kepuasan pelanggan terhadap loyalitas pada Pelanggan jasa JNE di Yogyakarta?

f. Apakah terdapat pengaruh positif kualitas layanan terhadap loyalitas melalui kepuasan pelanggan pada Pelanggan jasa JNE di Yogyakarta?

g. Apakah terdapat pengaruh positif citra merek terhadap loyalitas melalui kepuasan pelanggan pada Pelanggan jasa JNE di Yogyakarta?

\section{METODE PENELITIAN}

Penelitian ini yang dijadikan populasi adalah seluruh pelanggan jasa pengiriman JNE yang berdomisili di Yogayakarta. Sampel dalam penelitian ini yakni sebagian pelanggan dari pelanggan jasa JNE di Yogyakarta. Metode sampling yang digunakan dalam penelitian ini adalah purposive sampling. Dalam penelitian ini sampel yang diambil memiliki kriteria yaitu, pernah melakukan pengiriman minimal dua kali menggunakan jasa JNE di Yogyakarta. Teknik pengumpulan data pengambilan data pada penelitian ini berupa data primer didapatkan dari hasil tanggapan responden pada kuesioner yang disebar oleh peneliti. Penelitian ini dengan menggunakan kuesioner yang disebar secara online, dengan data yang diperoleh melalui google form yang berisi sejumlah tanggapan dari responden. Kuesioner tersebut meliputi variabel yang diteliti, yaitu kualitas layanan, citra merek, kepuasan pelanggan dan loyalitas pelanggan yang diukur menggunakan skala likert.

Pada penelitian ini, analisis yang digunakan yaitu analisis deskriptif dan analisis kuantitatif dengan metode SEM (Structural Equation Modeling), teknik analisis berbasis pada PLS (Partial Least Square).

$\mathrm{H}_{1} \quad$ : Kualitas Pelayanan berpengaruh positif terhadap Kepuasan Pelanggan pada Pelanggan jasa JNE di Yogyakarta.

$\mathrm{H}_{2} \quad$ : Citra Merek berpengaruh positif terhadap Kepuasan Pelanggan pada Pelanggan jasa JNE di Yogyakarta.

$\mathrm{H}_{3} \quad$ : Kualitas Layanan berpengaruh positif terhadap Loyalitas Pelanggan pada Pelanggan jasa JNE di Yogyakarta.

$\mathrm{H}_{4} \quad$ : Citra Merek berpengaruh positif terhadap Loyalitas Pelanggan pada Pelanggan jasa JNE di Yogyakarta.

$\mathrm{H}_{5} \quad$ : Kepuasan Pelanggan berpengaruh positif terhadap Loyalitas Pelanggan pada Pelanggan jasa JNE di Yogyakarta.

$\mathrm{H}_{6} \quad$ : Kualitas Layanan berpengaruh positif terhadap loyalitas pelanggan melalui kepuasan pelanggan pada Pelanggan jasa JNE di Yogyakarta. 
$\mathrm{H}_{7}$ : Citra Merek berpengaruh positif terhadap loyalitas pelanggan melalui kepuasan pelanggan pada Pelanggan jasa JNE di Yogyakarta.

\section{HASIL DAN PEMBAHASAN}

\section{Deskripsi Objek Penelitian}

JNE merupakan perusahaan jasa pengiriman barang yang memiliki layanan terbaik dan merek yang terkenal di Indonesia salah satunya adalah PT Tiki Jalur Nugraha Ekakurir atau sering disebut JNE adalah perusahaan milik swasta yang berdiri tahun 1990. JNE menjadi top of mind di Indonesia. Kebanyakan pelaku bisnis online dan jasa pengiriman barang atau kurir adalah pasangan yang tidak dapat dipisahkan. Jasa pegiriman barang atau kurir dapat membantu kebutuhan para pelaku bisnis untuk mengirimkan barang dari seller kepada customer dengan baik. Pelaku bisnis membutuhkan jasa pengiriman barang untuk memperluas jangkauan pasarnya.

abel 1 Karakteristik Responden

\begin{tabular}{|c|c|c|}
\hline Karakteristik & Frekuensi & Presentase (\%) \\
\hline Jenis Kelamin & 102 & $37,8 \%$ \\
\hline Laki-Laki & 168 & $62,2 \%$ \\
\hline Perempuan & 270 & $100 \%$ \\
\hline Jumlah & & $77,8 \%$ \\
\hline Usia & 210 & $14,1 \%$ \\
\hline $18-22$ tahun & 38 & $3 \%$ \\
\hline $23-27$ tahun & 8 & $5,2 \%$ \\
\hline $28-32$ tahun & 15 & $100 \%$ \\
\hline$>32$ tahun & 270 & $67,4 \%$ \\
\hline Jumlah & & $9,6 \%$ \\
\hline Pekerjaan & 182 & $4,8 \%$ \\
\hline Pelajar/ Mahasiswa & 26 & $7 \%$ \\
\hline Wiraswasta & 13 & $11,1 \%$ \\
\hline TNI/POLRI/PNS & 19 & $100 \%$ \\
\hline Karyawan Swasta & 30 & $37,8 \%$ \\
\hline Lainnya & 270 & $30,4 \%$ \\
\hline Jumlah & & $31,9 \%$ \\
\hline Frekuensi & 102 & $100 \%$ \\
\hline $2-3$ kali & 86 & \\
\hline $4-5$ kali & 270 & \\
\hline$>5$ kali & & \\
\hline Jumlah & & \\
\hline
\end{tabular}

\section{Analisis Deskriptif Variabel Penelitian}

\section{Variabel Kualitas Layanan}

Tabel 2 Tanggapan Responden Terhadap Kualitas Layanan

\begin{tabular}{|c|l|c|c|}
\hline Indikator & \multicolumn{1}{|c|}{ Pernyataan } & Mean & Keterangan \\
\hline KL1 & $\begin{array}{l}\text { Menggunakan peralatan yang } \\
\text { modern untuk melayani pelanggan, }\end{array}$ & 4,15 & Tinggi \\
\hline KL2 & Ruang pelayanan luas. & 3,97 & Tinggi \\
\hline KL3 & Karyawan berpenampilan rapi. & 4,08 & Tinggi \\
\hline KL4 & $\begin{array}{l}\text { Urusan yang sama dilayani dengan } \\
\text { waktu yang relatif sama. }\end{array}$ & 4,05 & Tinggi \\
\hline KL5 & $\begin{array}{l}\text { Karyawan mampu menangani } \\
\text { masalah keluhan pelanggan dengan } \\
\text { baik. }\end{array}$ & 4,16 & Tinggi \\
\hline KL6 & $\begin{array}{l}\text { Jenis layanan yang diberikan sesuai } \\
\text { dengan yang ditawarkan. }\end{array}$ & 4,17 & Sangat Tinggi \\
\hline KL7 & $\begin{array}{l}\text { Karyawan memberikan informasi } \\
\text { jelas pada pelanggan. }\end{array}$ & 4,25 & \\
\hline
\end{tabular}

Service Quality,

Brand Image and

Customer Loyalty to

Jne Customers

295 
Service Quality, Brand Image and Customer Loyalty to Jne Customers

\begin{tabular}{|c|l|c|c|}
\hline KL8 & $\begin{array}{l}\text { Karyawan memberikan layanan } \\
\text { tepat waktu bagi pelanggan. }\end{array}$ & 4,13 & Tinggi \\
\hline KL9 & $\begin{array}{l}\text { Karyawan cepat merespon } \\
\text { permintaan pelanggan. }\end{array}$ & 4,12 & Tinggi \\
\hline KL10 & $\begin{array}{l}\text { Karyawan memiliki pengetahuan } \\
\text { mengoperasikan komputer. }\end{array}$ & 4,27 & Sangat Tinggi \\
\hline KL11 & $\begin{array}{l}\text { Menjamin barang yang dikirim } \\
\text { sampai pada penerima dengan } \\
\text { cepat. }\end{array}$ & 4,17 & Tinggi \\
\hline KL12 & $\begin{array}{l}\text { Menjamin barang yang dikirim } \\
\text { sampai pada penerima dengan } \\
\text { aman. }\end{array}$ & 4,28 & Sangat Tinggi \\
\hline KL13 & $\begin{array}{l}\text { Karyawan sopan dalam melayani } \\
\text { pelanggan. }\end{array}$ & 4,27 & Sangat Tinggi \\
\hline KL14 & $\begin{array}{l}\text { Karyawan mudah dihubungi oleh } \\
\text { pelanggan. }\end{array}$ & 4,08 & Tinggi \\
\hline KL15 & $\begin{array}{l}\text { Karyawan memberikan perhatian } \\
\text { secara individual dalam melayani } \\
\text { pelanggan. }\end{array}$ & 3,95 & Tinggi \\
\hline KL16 & $\begin{array}{l}\text { Karyawan memahami kebutuhan } \\
\text { pelanggan. }\end{array}$ & 4,16 & Tinggi \\
\hline & Rata-rata & 4,14 & \\
\hline
\end{tabular}

Sumber: Output data diolah dari SmartPLS 3.0, 2021

Berdasarkan Tabel 4.6 diatas dari 270 responden yang diambil sebagai sampel, diketahui rata-rata responden yang menilai kualitas layanan pada pengguna jasa JNE di Yogyakarta termasuk kategori tinggi yaitu dengan nilai mean sebesar 4,14. Hal ini menunjukkan bahwa kualitas layanan JNE di Yogyakarta dapat disimpulkan JNE memberikan kualitas layanan yang baik atau sesuai dengan harapan pelanggan sehingga pelanggan merasa puas.

Variabel Citra Merek

Tanggapan Responden Terhadap Citra Merek

\begin{tabular}{|c|c|l|c|c|}
\hline Indikator & \multicolumn{1}{|c|}{ Pernyataan } & Mean & Keterangan \\
\hline CM1 & $\begin{array}{l}\text { JNE Yogyakarta } \\
\text { dikesankan sebagai } \\
\text { layanan ekspedisi } \\
\text { dikenal luas. }\end{array}$ & 4,40 & Sangat Baik \\
\hline CM2 & $\begin{array}{l}\text { JNE Yogyakarta } \\
\text { dikesankan sebagai } \\
\text { layanan ekspedisi } \\
\text { bereputasi baik. }\end{array}$ & 4,25 & Sangat Baik \\
\hline CM3 & $\begin{array}{l}\text { JNE Yogyakarta } \\
\text { dikesankan sebagai } \\
\text { layanan ekspedisi } \\
\text { pilihan ideal. }\end{array}$ & 4,22 & Sangat Baik \\
\hline & \multicolumn{1}{|l|}{ Rata-rata } & 4,29 & Sangat Baik \\
\hline
\end{tabular}

Sumber: Output data diolah dari SmartPLS 3.0, 2021

Berdasarkan Tabel 4.7 diatas dari 270 responden yang diambil sebagai sampel, diketahui rata-rata responden yang menilai citra merek pada pengguna jasa JNE di Yogyakarta termasuk kategori sangat tinggi yaitu dengan nilai mean sebesar 4,29. Dapat disimpulkan bahwa citra merek yang sangat baik bagi jasa JNE di Yogyakarta membentuk loyalitas pelanggan sehingga perusahaan mampu mempertahankan pelanggan. 
Variabel Kepuasan Pelanggan

Tanggapan Responden Terhadap Kepuasan Pelanggan

\begin{tabular}{|c|l|c|c|}
\hline Indikator & \multicolumn{1}{|c|}{ Pernyataan } & Mean & Keterangan \\
\hline KP1 & $\begin{array}{l}\text { Saya puas dengan kemudahan akses } \\
\text { lokasi di JNE Yogyakarta. }\end{array}$ & 4,33 & Sangat Tinggi \\
\hline KP2 & $\begin{array}{l}\text { Saya puas dengan kenyamanan parkir } \\
\text { di JNE Yogyakarta. }\end{array}$ & 3,96 & Tinggi \\
\hline KP3 & $\begin{array}{l}\text { Saya puas dengan kecepatan antrian } \\
\text { di JNE Yogyakarta. }\end{array}$ & 4,00 & Tinggi \\
\hline KP4 & $\begin{array}{l}\text { Saya puas dengan penyelesaian order } \\
\text { di JNE Yogyakarta. }\end{array}$ & 4,14 & Tinggi \\
\hline KP5 & $\begin{array}{l}\text { Saya puas dengan kelancaran } \\
\text { pembayaran di JNE Yogyakarta. }\end{array}$ & 4,28 & Sangat Tinggi \\
\hline \multicolumn{1}{|c|}{ Rata-rata } & 4,14 & Tinggi \\
\hline
\end{tabular}

Service Quality,

Brand Image and

Customer Loyalty to

Jne Customers

Sumber: Output data diolah dari SmartPLS 3.0, 2021

Berdasarkan Tabel 4.8 diatas dari 270 responden yang diambil sebagai sampel, diketahui rata-rata responden yang menilai kepuasan pelanggan pada pengguna jasa JNE di Yogyakarta termasuk kategori tinggi yaitu dengan nilai mean sebesar 4,14. Dapat disimpulkan bahwa JNE di Yogyakarta memberikan pelayanan yang baik sehingga dapat menciptakan kepuasan pelanggan serta sesuai dengan harapan pelanggan.

Variabel Loyalitas Pelanggan

Tanggapan Responden Terhadap Loyalitas Pelanggan

\begin{tabular}{|c|l|c|c|}
\hline Indikator & \multicolumn{1}{|c|}{ Pernyataan } & Mean & Keterangan \\
\hline LP1 & $\begin{array}{l}\text { Saya bersedia menggunakan kembali } \\
\text { jasa pengiriman JNE Yogyakarta. }\end{array}$ & 4,26 & Sangat Tinggi \\
\hline LP2 & $\begin{array}{l}\text { Saya bersedia mengatakan hal-hal } \\
\text { positif tentang JNE Yogyakarta } \\
\text { kepada orang lain. }\end{array}$ & 4,21 & Tinggi \\
\hline LP3 & $\begin{array}{l}\text { Saya bersedia merekomendasikan JNE } \\
\text { kepada orang lain. }\end{array}$ & 4,18 & Tinggi \\
\hline \multicolumn{1}{|c|}{ Rata-rata } & 4,21 & Tinggi \\
\hline
\end{tabular}

Sumber: Output data diolah dari SmartPLS 3.0, 2021

Berdasarkan Tabel 4.9 diatas dari 270 responden yang diambil sebagai sampel, diketahui rata-rata responden yang menilai loyalitas pelanggan pada pengguna jasa JNE di Yogyakarta termasuk kategori tinggi yaitu dengan nilai mean sebesar 4,21. Dapat disimpulkan bahwa jasa JNE di Yogyakarta mampu menciptakan kepuasan yang tinggi bagi pelanggan sehingga pelanggan merasa loyal terhadap jasa JNE di Yogyakarta dan mampu mendorong pelanggan untuk kembali menggunakan jasa tersebut.

\section{Analisis Kuantitatif}

Pada penelitian ini menggunakan teknik pengolahan data metode SEM berbasis Partial Least Square (PLS) memerlukan 2 tahap. Menurut Chin, (1998) dalam Ghozali \& Latan (2015), hasil analisis PLS menggunakan pendekatan dua langkah atau two step approach. Pertama difokuskan untuk hasil dari pengukuran (Outer model) dan yang kedua difokuskan untuk hasil dari model struktural (Inner model). 
Service Quality, Brand Image and Customer Loyalty to Jne Customers

\section{Analisis Hasil Pengukuran atau Outer Model}

Pada penelitian ini terdapat kriteria dalam menguji indikator penggunaan teknik analisis data dengan SmartPLS 3.0 untuk menilai validitas dan reliabilitas dengan Outer

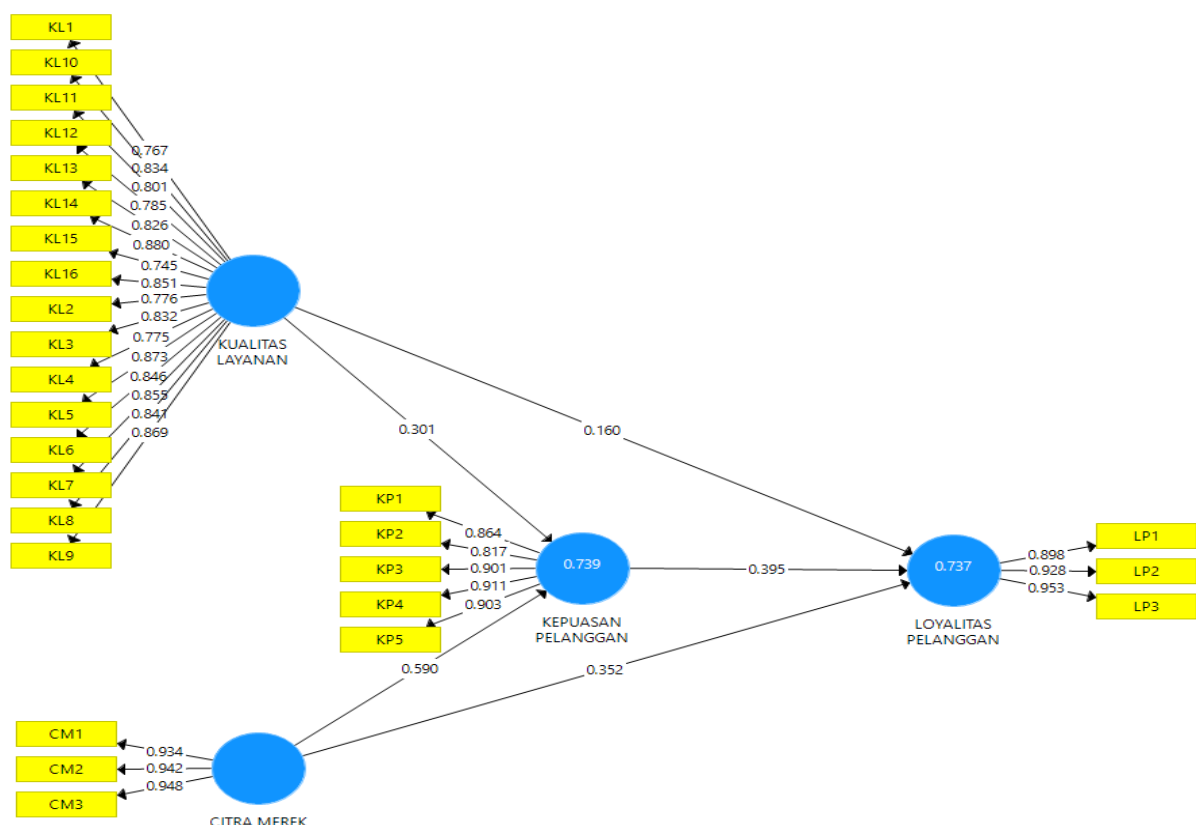

Model melalui convergent validity, discriminant validity, composite reliability, dan average variance extracted.

Gambar 1 Hasil Pengujian Outer Model

Sumber: Output data diolah dari SmartPLS 3.0, 2021

Tabel 3 Hasil Uji Validitas Konvergen

Outer Loading Factor Hasil Output PLS

\begin{tabular}{|c|c|c|c|c|}
\hline & $\begin{array}{l}\text { Kualitas } \\
\text { Layanan }\end{array}$ & $\begin{array}{l}\text { Citra } \\
\text { Merek }\end{array}$ & $\begin{array}{l}\text { Kepuasan } \\
\text { Pelanggan }\end{array}$ & $\begin{array}{l}\text { Loyalitas } \\
\text { Pelanggan }\end{array}$ \\
\hline KL1 & 0.767 & & & \\
\hline KL2 & 0.776 & & & \\
\hline KL3 & 0.832 & & & \\
\hline KL4 & 0.775 & & & \\
\hline KL5 & 0.873 & & & \\
\hline KL6 & 0.846 & & & \\
\hline KL7 & 0.855 & & & \\
\hline KL8 & 0.841 & & & \\
\hline KL9 & 0.869 & & & \\
\hline KL10 & 0.834 & & & \\
\hline KL11 & 0.801 & & & \\
\hline$\overline{\text { KL12 }}$ & 0.785 & & & \\
\hline KL13 & 0.826 & & & \\
\hline KL14 & 0.880 & & & \\
\hline KL15 & 0.745 & & & \\
\hline KL16 & 0.851 & & & \\
\hline CM1 & & 0.934 & & \\
\hline CM2 & & 0.942 & & \\
\hline CM3 & & 0.948 & & \\
\hline KP1 & & 0.864 & & \\
\hline KP2 & & & 0.817 & \\
\hline KP3 & & & 0.901 & \\
\hline
\end{tabular}


Sumber: Output data diolah dari SmartPLS 3.0, 2021

Berdasarkan sajian dalam Tabel diatas, diketahui bahwa masing-masing indikator memiliki nilai outer loading $>0.7$. Menurut Ghozali \& Latan (2015) nilai outer loading factor $>0.7$ sudah dianggap sangat baik untuk memenuhi syarat convergent validity. Data pada tabel 4.10 menunjukkan masing-masing indikator variabel memiliki nilai $>0.7$, sehingga semua indikator layak atau valid.

\section{Discriminant Validity}

Cross Loading

\section{Kualitas}

Layanan

\section{Citra Merek}

0.572

0.776

KL2 0.776

KL3 0.832

KL4 0.775

KL5 0.873

KL6 0.846

KL7 0.855

KL8 0.841

$\begin{array}{ll}\text { KL9 } & 0.869\end{array}$

KL10 0.834

KL11 0.801

KL12 0.785

KL13 0.826

KL14 0.880

KL15 0.745

KL16 0.851

CM1 0.823

CM2 0.801

CM3 0.767

KP1 0.774

KP2 0.63

KP3 0.656

KP4 0.682

KP5 0.761

LP1

LP2

LP3

0.761

0.602

0.575

0.596

0.726

0.574

0.641

0.713

0.682

0.688

0.721

0.690

0.594

0.739

0.660

0.703

0.934

0.942

0.788

0.622

0.726

0.719

0.734

0.765

0.782

Kepuasan pelanggan

\section{Loyalitas Pelanggan}

$0.574 \quad 0.596$

0.602

0.633

0.575

0.632

0.596

0.615

0.726

0.677

0.574

0.627

0.641

0.591

0.713

0.683

0.682

0.663

0.688

0.613

0.721

0.672

0.690

0.651

0.594

0.599

0.739

0.663

0.660

0.629

0.703

0.626

0.784

0.740

0.775

0.780

0.825

0.798

0.864

0.705

0.817

0.620

0.901

0.706

0.911

0.785

0.903

0.779

0.768

0.898

0.753

0.928

0.760

0.953

Sumber: Output data diolah dari SmartPLS 3.0, 2021 pada variabel penelitian ini dapat diketahui memiliki hasil uji discriminant validity
atau nilai cross loading factor $>0,7$ sehingga semua dianggap valid. Maka dapat disimpulkan bahwa hasil yang diperoleh diatas dinyatakan bahwa indikator-indikator 
Service Quality, Brand Image and Customer Loyalty to Jne Customers yang digunakan dalam penelitian ini telah memiliki discriminant validity yang baik dalam menyusun masing-masing variabelnya. Average Variance Extracted (AVE)

\begin{tabular}{c|c|c|c} 
Variabel & AVE & Kriteria & Keterangan \\
\hline Kualitas Layanan & 0,678 & $>0,5$ & Valid \\
\hline Citra Merek & 0,887 & $>0,5$ & Valid \\
\hline Kepuasan Pelanggan & 0,774 & $>0,5$ & Valid \\
\hline Loyalitas Pelanggan & 0,858 & $>0,5$ & Valid
\end{tabular}

Sumber: Output data diolah dari SmartPLS 3.0, 2021

Tabel 4 Uji Reliabilitas

\begin{tabular}{c|c|c|c} 
Variabel & $\begin{array}{c}\text { Composite Reliability } \\
\text { Composite Reliability }\end{array}$ & Kriteria & Keterangan \\
\hline Kualitas Layanan & 0,971 & $>0,7$ & Reliabel \\
\hline Citra Merek & 0,959 & $>0,7$ & Reliabel \\
\hline Kepuasan Pelanggan & 0,945 & $>0,7$ & Reliabel \\
\hline Loyalitas Pelanggan & 0,948 & $>0,7$ & Reliabel
\end{tabular}

Sumber: Output data diolah dari SmartPLS 3.0, 2021

Cronbach's Alpha

\begin{tabular}{cccc} 
Variabel & Cronbach's Alpha & Kriteria & Keterangan \\
\hline Kualitas Layanan & 0,968 & $>0,7$ & Reliabel \\
\hline Citra Merek & 0,936 & $>0,7$ & Reliabel \\
\hline Kepuasan Pelanggan & 0,927 & $>0,7$ & Reliabel \\
\hline Loyalitas Pelanggan & 0,917 & $>0,7$ & Reliabel
\end{tabular}

Sumber: Output data diolah dari SmartPLS 3.0, 2021

Analisis Hasil Pengujian Model Struktural (Inner Model)

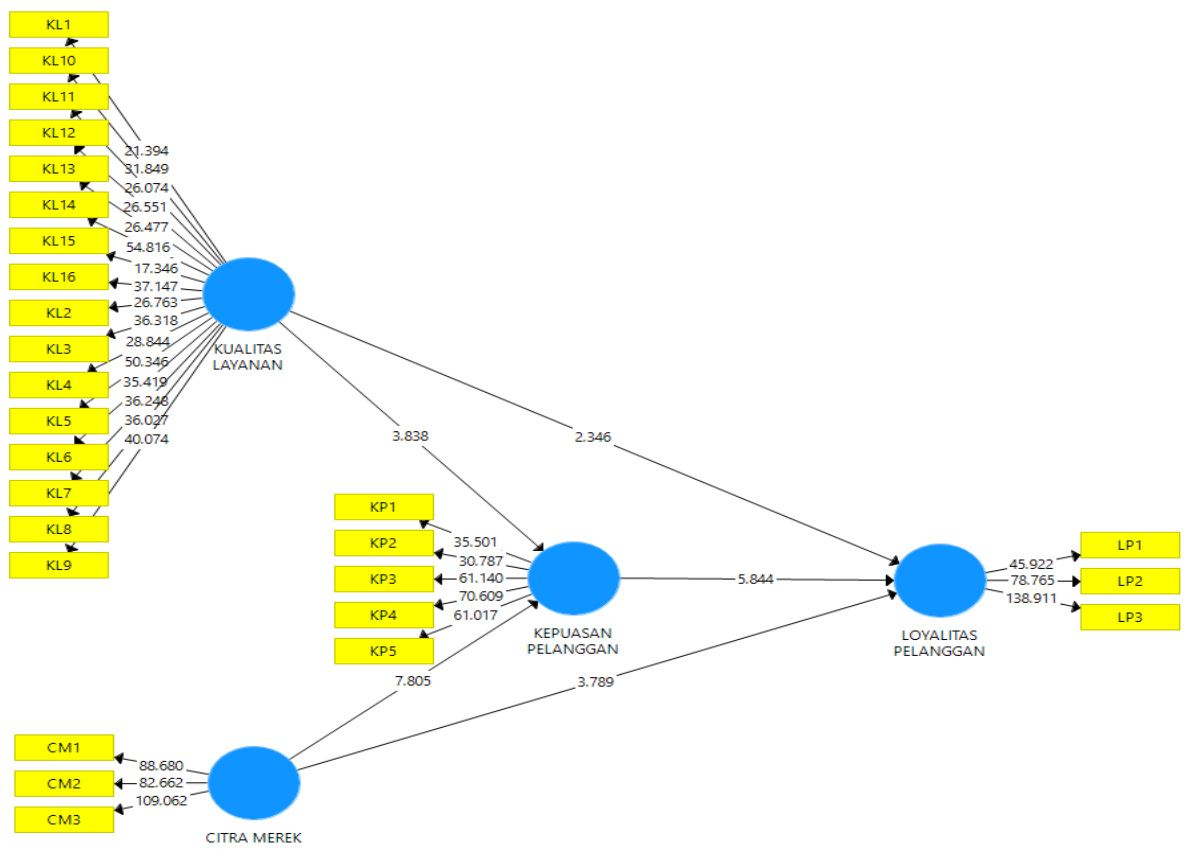

Gambar 2 Hasil Pengujian Inner Model

Sumber: Output data diolah dari SmartPLS 3.0, 2021 
Tabel 5 Hasil Uji Inner Model Struktural

R Square

\begin{tabular}{lcc} 
& R Square & R Square Adjusted \\
\hline KEPUASAN PELANGGAN & 0.739 & 0.737 \\
\hline LOYALITAS PELANGGAN & 0.737 & 0.734 \\
Sumber : Output data diolah dari SmartPLS & $3.0,2021$ &
\end{tabular}

\begin{tabular}{|c|c|c|}
\hline Pengujian & Hasil Uji & Kriteria \\
\hline $\begin{array}{l}\text { Koefisien Determinan (R- } \\
\underline{\text { Square) }} \\
\text { Kepuasan Pelangan (R1) }\end{array}$ & 0.739 & Baik \\
\hline Loyalitas pelanggan (R2) & 0.737 & \\
\hline $\begin{array}{l}Q^{2} \text { Predictive Relevance } \\
\mathrm{Q}^{2}=1-\left(1-\mathrm{R} 1^{2}\right)\left(1-\mathrm{R} 2^{2}\right) \\
=1-(1-0,739)^{2}(1-0,737)^{2} \\
=1-(1-0,546)(1-0,543) \\
=1-(0,454)(0,457) \\
=1-(0,207) \\
=0,793\end{array}$ & $79,3 \%$ & $\begin{array}{l}\text { Baik, artinya bahwa nilai- } \\
\text { nilai yang diobservasikan } \\
\text { sudah direkonstruksi dengan } \\
\text { baik dengan mempunyai } \\
\text { relevansi prediktif }\end{array}$ \\
\hline P-Value & & \\
\hline $\begin{array}{l}\text { Kualitas Layanan }(\mathrm{X} 1)=> \\
\text { Kepuasan Pelanggan }(\mathrm{Z})\end{array}$ & 0.000 & Signifikan \\
\hline $\begin{array}{l}\text { Citra Merek }(X 2)=> \\
\text { Kepuasan Pelanggan }(Z)\end{array}$ & 0.000 & Signifikan \\
\hline $\begin{array}{l}\text { Kualitas Layanan }(\mathrm{X} 1)=> \\
\text { Loyalitas Pelanggan }(\mathrm{Y})\end{array}$ & 0.019 & Signifikan \\
\hline $\begin{array}{l}\text { Citra Merek }(\mathrm{X} 2)=>\text { Loyalitas } \\
\text { Pelanggan }(\mathrm{Y})\end{array}$ & 0.000 & Signifikan \\
\hline $\begin{array}{l}\text { Kepuasan Pelanggan }(\mathrm{Z})=> \\
\text { Loyalitas Pelanggan }(\mathrm{Y})\end{array}$ & 0.000 & Signifikan \\
\hline $\begin{array}{l}\text { Kualitas Layanan }(\mathrm{X} 1)=> \\
\text { Kepuasan Pelanggan }(\mathrm{Z})=> \\
\text { Loyalitas Pelanggan }(\mathrm{Y})\end{array}$ & 0.003 & Signifikan \\
\hline $\begin{array}{l}\text { Citra Merek }(\mathrm{X} 2)=> \\
\text { Kepuasan Pelanggan }(\mathrm{Z})=> \\
\text { Loyalitas Pelanggan }(\mathrm{Y})\end{array}$ & 0.000 & Signifikan \\
\hline
\end{tabular}

Sumber: Output data diolah dari SmartPLS 3.0, 2021

\section{Penafsiran :}

\section{a. Uji R-Square atau koefisien determinan $\left(\mathbf{R}^{2}\right)$}

R-Square (Coefficient Determination) digunakan untuk mengukur seberapa banyak variabel endogen dipengaruhi oleh variabel lainnya. Pada tabel 4.15 menunjukkan bahwa variabel kepuasan pelanggan dipengaruhi oleh variabel kualitas layanan dan citra merek sebesar $73,9 \%$ dan sisanya sebesar $26,1 \%$ dipengaruhi oleh faktor lain yang tidak terdapat dalam model. Sedangkan loyalitas pelanggan dipengaruhi kepuasan pelanggan sebesar 73,7\% dan sisanya sebesar 26,3 dipengaruhi oleh faktor lain yang tidak terdapat dalam model.

b. Uji Goodness-of-Fit
Service Quality,

Brand Image and

Customer Loyalty to

Jne Customers 
Service Quality,

Brand Image and

Customer Loyalty to

Jne Customers

302
Penilaian dari goodness of fit diketahui dari nilai Q-Square predictive relevance. Nilai Q-Square memiliki arti yang sama dengan coefficient determination (R-Square) pada analisis regresi, dimana semakin tinggi Q-Square, maka model dapat dikatakan semakin baik atau semakin fit dengan data . perhitungan Q-Square sebagai berikut :

$$
\begin{aligned}
\text { Q-Square }\left(\mathrm{Q}^{2}\right)=1 & -\left(1-\mathrm{R} 1^{2}\right)\left(1-\mathrm{R} 2^{2}\right) \\
& =1-(1-0,739)^{2}(1-0,737)^{2} \\
& =1-(1-0,546)(1-0,543) \\
& =1-(0,454)(0,457) \\
& =1-(0,207) \\
& =0,793
\end{aligned}
$$

Berdasarkan hasil perhitungan diatas, memperoleh nilai Q-Square (Q2) sebesar 0,793 . Hal ini menunjukkan besarnya keragaman dalam penelitian yang dapat dijelaskan oleh model penelitian adalah sebesar 79,3\%. Sedangkan sisanya sebesar 20,7\% dijelaskan oleh faktor lain yang berada diluar model penelitian ini. Dengan demikian, dari hasil tersebut maka model penelitian ini dapat dinyatakan

\begin{tabular}{|c|c|c|c|c|c|}
\hline \multicolumn{6}{|l|}{. } \\
\hline Variabel & $\begin{array}{l}\text { Original } \\
\text { Sample } \\
\text { (O) }\end{array}$ & $\begin{array}{c}\text { Sample } \\
\text { Mean } \\
\text { (M) }\end{array}$ & $\begin{array}{l}\text { Standard } \\
\text { Deviation } \\
\text { (STDEV) }\end{array}$ & $\begin{array}{c}\text { T Statistics } \\
(|\mathrm{O} / \mathrm{STDEV}|)\end{array}$ & P Values \\
\hline $\begin{array}{c}\text { Kualitas } \\
\text { Layanan - } \\
> \\
\text { Kepuasan } \\
\text { Pelanggan } \\
\end{array}$ & 0.301 & 0.300 & 0.078 & 3.838 & 0.000 \\
\hline $\begin{array}{c}\text { Citra } \\
\text { Merek -> } \\
\text { Kepuasan } \\
\text { Pelanggan }\end{array}$ & 0.352 & 0.351 & 0.093 & 3.789 & 0.000 \\
\hline $\begin{array}{c}\text { Kualitas } \\
\text { Layanan - } \\
\text { > Loyalitas } \\
\text { Pelanggan } \\
\end{array}$ & 0.160 & 0.161 & 0.068 & 2.346 & 0.019 \\
\hline $\begin{array}{c}\text { Citra } \\
\text { Merek -> } \\
\text { Loyalitas } \\
\text { Pelanggan } \\
\end{array}$ & 0.352 & 0.351 & 0.093 & 3.789 & 0.000 \\
\hline $\begin{array}{c}\text { Kepuasan } \\
\text { Pelanggan } \\
\text {-> } \\
\text { Loyalitas } \\
\text { Pelanggan }\end{array}$ & 0.395 & 0.393 & 0.068 & 5.844 & 0.000 \\
\hline umber: Outp & di 1. & Smar & 2021 & & \\
\hline
\end{tabular}
telah memiliki goodness of fit yang baik.

c. P-Value

Semua variabel dalam penelitian dinyatakan memiliki pengaruh yang signifikan karena memiliki P-Value $<0,05$ (signifikan 5\%)

Tabel 6 Hasil Uji t Statistik 


\begin{tabular}{|c|c|c|c|c|c|c|}
\hline \multicolumn{7}{|c|}{ Indirect Effect } \\
\hline Variabel & $\begin{array}{l}\text { Original } \\
\text { Sample } \\
\text { (O) }\end{array}$ & $\begin{array}{l}\text { Sample } \\
\text { Mean } \\
\text { (M) }\end{array}$ & $\begin{array}{l}\text { Standard } \\
\text { Deviation } \\
\text { (STDEV) }\end{array}$ & $\begin{array}{l}\text { T Statistics } \\
(\mid \mathrm{O} / \mathrm{STDE} \\
\mathrm{V} \mid)\end{array}$ & $\begin{array}{l}\text { P } \\
\text { Val } \\
\text { ues }\end{array}$ & $\begin{array}{c}\text { Kete } \\
\text { rang } \\
\text { an }\end{array}$ \\
\hline $\begin{array}{l}\text { KUALITAS LAYANAN -> KEPUASAN } \\
\text { PELANGGAN -> LOYALITAS } \\
\text { PELANGGAN }\end{array}$ & 0.119 & 0.118 & 0.039 & 3.036 & $\begin{array}{r}0.0 \\
03\end{array}$ & $\begin{array}{l}\text { Diter } \\
\text { ima }\end{array}$ \\
\hline $\begin{array}{l}\text { CITRA MEREK -> KEPUASAN } \\
\text { PELANGGAN -> LOYALITAS } \\
\text { PELANGGAN }\end{array}$ & 0.233 & 0.230 & 0.048 & 4.900 & $\begin{array}{r}0.0 \\
00\end{array}$ & $\begin{array}{l}\text { Diter } \\
\text { ima }\end{array}$ \\
\hline
\end{tabular}

Pembahasan

Sumber: Output data diolah dari SmartPLS 3.0, 2021

\section{Pengaruh Kualitas Layanan terhadap Kepuasan Pelanggan}

Penelitian ini menunjukkan hipotesis 1 bahwa kualitas layanan berpengaruh positif terhadap kepuasan pelanggan pada pelanggan jasa JNE di Yogyakarta. Penelitian ini menunjukkan adanya pengaruh positif kualitas layanan terhadap kepuasan pelanggan, artinya semakin baik kualitas layanan yang diberikan jasa JNE di Yogyakarta, maka akan semakin meningkatkan kepuasan pelanggan. Oleh karena itu, sangat penting bagi jasa JNE di Yogyakarta untuk mempertahankan kualitas layanannya tetap baik bagi pelanggan.

Pelanggan jasa JNE di Yogyakarta akan merasa puas jika diberikan pelayanan yang baik dan sesuai dengan harapannya. Hasil penelitian ini mendukung teori Lupiyodi (2001) untuk industri jasa pelanggan akan merasa puas jika mereka mendapatkan pelayanan yang baik sesuai dengan yang diharapkan. Sebaliknya apabila pelanggan mendapat pelayanan yang tidak baik maka mereka akan merasa tidak puas. Hasil penelitian ini mendukung penelitian Dimyati \& Subagio (2016), Lise \& Sitio (2019), Nastiti \& Astuti (2019) dan Syahputra (2020) yang membuktikan bahwa kualitas layanan memiliki pengaruh positif terhadap kepuasan pelanggan. Dapat disimpulkan bahwa semakin baik kualitas layanan dan sesuai dengan harapan pelanggan akan mendorong kepuasan pelanggan.

\section{Pengaruh Citra Merek terhadap Kepuasan Pelanggan}

Penelitian ini menunjukkan hipotesis 2 bahwa citra merek berpengaruh positif terhadap kepuasan pelanggan pada pelanggan jasa JNE di Yogyakarta. Citra merek memiliki pengaruh kuat terhadap kepuasan pelanggan. Penelitian ini menunjukkan adanya pengaruh positif citra merek terhadap kepuasan pelanggan, artinya semakin bereputasi baik citra merek jasa JNE di Yogyakarta, maka akan semakin meningkatkan kepuasan pelanggan. Oleh karena itu, sangat penting bagi jasa JNE di Yogyakarta untuk mempertahankan reputasinya agar menimbulkan nilai positif dibenak pelanggan dan mendorong kepuasan pelanggan.

Hasil penelitian ini mendukung teori Kotler \& Keller (2016) citra merek mengambarkan sifat ekstrinsik produk atau layanan termasuk cara-cara yang dilakukan upaya merek untuk memenuhi kebutuhan psikologis atau kebutuhan pelanggan. Hasil penelitian ini mendukung penelitian Dimyati \& Subagio (2016), Lise \& Sitio (2019), Nastiti \& Astuti (2019) dan Syahputra (2020) yang membuktikan bahwa citra merek memiliki pengaruh positif terhadap kepuasan pelanggan. Dapat disimpulkan bahwa semakin citra merek menimbulkan nilai positif maka pelanggan akan percaya terhadap merek tersebut, sehingga akan menimbulkan kepuasan bagi penggunanya. Sebaliknya jika citra merek tidak menimbulkan nilai positif pada pelanggan maka pelanggan tidak atau akan kurang percaya pada merek tersebut.

\section{Pengaruh Kualitas Layanan terhadap Loyalitas Pelanggan}

Penelitian ini menunjukkan hipotesis 3 bahwa kualitas layanan berpengaruh positif terhadap loyalitas pelanggan pada pelanggan jasa JNE di Yogyakarta. Penelitian ini menunjukkan adanya pengaruh positif kualitas layanan terhadap loyalitas pelanggan, artinya baik kualitas layanan yang dimiliki jasa JNE di Yogyakarta, maka semakin meningkatkan loyalitas pelanggan. Ketika jasa JNE di Yogyakarta memberikan kualitas layanan yang baik dan sesuai dengan harapan pelanggan akan menimbulkan loyalitas pelanggan. 
Service Quality,

Brand Image and

Customer Loyalty to

Jne Customers

304

Hasil penelitian ini mendukung Kotler dan Amstrong (2001) membuat pelanggan tetap bertahan merupakan ukuran terbaik untuk kualitas atas kemampuan perusahaan dalam mempertahankan pelanggannya, tergantung pada konsistensi perusahaan menyampaikan nilai kepada pelanggan. Hasil penelitian ini mendukung penelitian Dimyati \& Subagio (2016), Lise \& Sitio (2019), Nastiti \& Astuti (2019) dan Syahputra (2020) yang membuktikan bahwa kualitas layanan memiliki pengaruh positif terhadap loyalitas pelanggan. Dapat disimpulkan bahwa kualitas layanan sangat mempengaruhi loyalitas pelanggan. Ketika pelanggan mendapatkan layanan yang terbaik dari jasa JNE di Yogyakarta dan sesuai dengan harapan pelanggan maka akan mendorong loyalitas pelanggan atau perusahaan mampu mempertahankan pelanggannya.

\section{Pengaruh Citra Merek terhadap Loyalitas Pelanggan}

Penelitian ini menunjukkan hipotesis 4 bahwa citra merek berpengaruh positif terhadap loyalitas pelanggan pada pelanggan jasa JNE di Yogyakarta. Terdapat hubungan yang kuat citra merek dengan loyalitas pelanggan pada jasa JNE di Yogyakarta. Oleh karena itu, citra merek harus dipertahankan karena untuk meningkatkan loyalitas pelanggan.

Hasil penelitian ini mendukung teori Kotler \& Amstrong (2001) citra merupakan nilai nyata dari sebuah merek yang kekuatannya untuk menangkap preferensi dan loyalitas pelanggan. Pentingnya citra merek yang positif dalam jasa JNE di Yogyakarta mampu memberikan kesan positif kepada pelanggan Hasil penelitian ini tidak mendukung penelitian Dimyati \& Subagio (2016) yang membuktikan bahwa citra merek berpengaruh positif dan tidak signifikan terhadap loyalitas pelanggan. Namun mendukung penelitian Lise \& Sitio (2019), Nastiti \& Astuti (2019) dan Syahputra (2020) yang membuktikan bahwa citra merek memiliki pengaruh positif terhadap loyalitas pelanggan. Dapat disimpulkan bahwa citra merek jasa JNE di Yogyakarta memiliki reputasi baik yang menimbulkan kesan positif dibenak pelanggan dan semakin baik citra merek akan semakin mendorong loyalitas pelanggan.

\section{Pengaruh Kepuasan Pelanggan terhadap Loyalitas Pelanggan}

Penelitian ini menunjukkan hipotesis 5 bahwa kepuasan pelanggan berpengaruh positif terhadap loyalitas pelanggan pada pelanggan jasa JNE di Yogyakarta. Semakin tinggi kepuasan pelanggan terhadap jasa JNE di Yogyakarta akan semakin meningkatkan loyalitas pelanggan. Loyalitas pelanggan dapat terbentuk jika pelanggan merasa puas dengan merek yang diterima dan berniat untuk melanjutkan hubungan. Terdapat hubungan yang kuat antara kepuasan pelanggan dengan loyalitas pelanggan pada jasa JNE di Yogyakarta. Dengan begitu kepuasan pelanggan harus dipertahankan dan terus ditingkatkan kearah yang lebih baik lagi karena dapat meningkatkan loyalitas pelanggan.

Hasil penelitian ini mendukung teori Tjiptono (2018), mengungkapkan bahwa kepuasan pelanggan merupakan evaluasi purnabeli dimana alternatif yang dipilih sekurang-kurangnya memberikan hasil (outcome) atau melampaui harapan pelanggan, sedangkan ketidakpuasan timbul apabila hasil yang diperoleh tidak memenuhi harapan pelanggan. Hasil penelitian ini mendukung penelitian Dimyati \& Subagio (2016), Lise \& Sitio (2019), Nastiti \& Astuti (2019) dan Syahputra (2020) yang membuktikan bahwa kepuasan pelanggan memiliki pengaruh positif terhadap loyalitas pelanggan. dapat disimpulkan bahwa ketika pelanggan merasa puas maka akan membangun loyalitas pelanggan pada jasa JNE di Yogyakarta.

\section{Pengaruh Kualitas Layanan terhadap Loyalitas Pelanggan melalui Kepuasan Pelanggan}

Kepuasan pelanggan merupakan faktor yang kuat dalam menentukan loyalitas pelanggan. Walaupun kualitas layanan yang baik menimbulkan presepsi pelanggan terhadap kualitas layanan juga baik dan sesuai dengan harapan pelanggan, namun untuk menimbulkan loyalitas pelanggan diperlukan adanya rasa puas yang dirasakan oleh pelanggan jasa JNE di Yogyakarta. Oleh karena itu, kepuasan pelanggan harus terus dipertahankan ataupun ditingkatkan lebih baik lagi yang akan mendorong loyalitas pelanggan jasa JNE di Yogyakarta. 
Berdasarkan hasil analisis bootstrapping dalam penelitian ini menunjukkan bahwa kualitas layanan berpengaruh tidak langsung terhadap loyalitas pelanggan melalui kepuasan pelanggan, hal tersebut menunjukkan bahwa kepuasan pelanggan mampu memediasi kualitas layanan terhadap loyalitas pelanggan. Sehingga, hal tersebut menunjukkan bahwa kepuasan pelanggan yang dirasakan atas kualitas layanan yang baik akan menimbulkan loyalitas pelanggan.

Hasil penelitianini mendukung teori Dimyati \& Subagio (2016), kulitas layanan yang baik akan memuaskan pelanggan dan mempengaruhi pada terciptanya loyalitas pelanggan. kualitas merupakan sesuatu yang dirasakan pelanggan untuk memenuhi harapannya. Pelayanan yang baik akan memberikan kepuasan kepada pelanggan atau mampu memberikan pelayanan yang melebihi harapannya. Loyalitas yang timbul dipengaruhi oleh kepuasan, apabila pelanggan merasa puas pada layanan yang baik atas apa yang diterima dan sesuai dengan harapan maka akan berdampak pada loyalitas pelanggan. Hasil penelitian ini mendukung penelitian Syahputra (2020), membuktikan bahwa kualitas layanan berpengaruh positif dan dan signifikan terhadap loyalitas pelanggan melalui kepuasan pelanggan. dapat disimpulkan bahwa kepuasan pelanggan mampu memediasi pengaruh kualitas layanan terhadap loyalitas pelanggan jasa JNE di Yogyakarta.

\section{Pengaruh Citra Merek terhadap Loyalitas Pelanggan melalui Kepuasan Pelanggan}

Kepuasan pelanggan merupakan faktor yang kuat dalam menentukan loyalitas pelanggan. Walaupun citra merek yang memiliki reputasi baik menimbulkan presepsi positif dan dapat membuat pelanggan percaya pada merek tersebut, namun untuk mendorong loyalitas pelanggan diperlukan adanya adanya perasaan puas yang dirasakan oleh pelanggan jasa JNE di Yogyakarta.

Berdasarkan hasil analisis bootstrapping dalam penelitian ini menunjukkan bahwa citra merek berpengaruh tidak langsung terhadap loyalitas pelanggan melalui kepuasan pelanggan, hal tersebut menunjukkan bahwa kepuasan pelanggan mampu memediasi citra merek terhadap loyalitas pelanggan. Sehingga, hal tersebut menunjukkan bahwa kepuasan pelanggan yang dirasakan atas kesesuaian citra merek yang baik akan menimbulkan loyalitas pelanggan.

Hasil penelitian ini mendukung teori Sutisna (2001), konsumen dengan citra positif terhadap suatu merek akan melakukan pembelian ulang. Merek memberikan kesan tersendiri kepada pelanggan akan menimbulkan prespsi positif bagi pelanggan yang menimbulkan kepuasan. Melalui kepuasan pelanggan akan menimbulkan loyalitas pelanggan, dimana ketika kinerja melebihi apa yang diharapkan maka pelanggan akan puas dan akan kembali membeli atau menggunakan produk atau jasa tersebut. Hasil penelitian ini mendukung penelitian Syahputra (2020) yang membuktikan bahwa citra merek berpengaruh positif dan dan signifikan terhadap loyalitas pelanggan melalui kepuasan pelanggan. dapat disimpulkan bahwa kepuasan pelanggan mampu memediasi pengaruh citra merek terhadap loyalitas pelanggan jasa JNE di Yogyakarta.

\section{PENUTUP}

\section{Kesimpulan}

Berdasarkan hasil penelitian untuk mengetahui pengaruh Kualitas Layanan dan Citra Merek terhadap Loyalitas Pelanggan melalui Kepuasan Pelanggan pada Pelanggan Jasa JNE di Yogyakarta. Untuk menganalisis pengaruh antar variabel tersebut, penelitian ini menggunakan Partial Least Square (PLS). dari hasil analisis data dan pembahasan yang telah diuraikan, maka dapat ditarik kesimpulan sebagai berikut: Kualitas Pelayanan berpengaruh positif dan signifikan terhadap Kepuasan Pelanggan pada pengguna jasa JNE di Yogyakarta, Citra Merek berpengaruh positif dan signifikan terhadap Kepuasan Pelanggan pada pengguna jasa JNE di Yogyakarta, Kualitas Layanan berpengaruh positif dan signifikan terhadap Loyalitas Pelanggan pada pengguna jasa JNE di Yogyakarta, Citra Merek berpengaruh positif dan signifikan terhadap Loyalitas Pelanggan pada pengguna jasa JNE di Yogyakarta, Kepuasan Pelanggan berpengaruh positif dan signifikan terhadap Loyalitas Pelanggan pada pengguna jasa JNE di Yogyakarta, Kualitas Layanan berpengaruh positif dan signifikan terhadap loyalitas pelanggan
Service Quality,

Brand Image and

Customer Loyalty to

Jne Customers 
Service Quality, Brand Image and Customer Loyalty to Jne Customers melalui kepuasan pelanggan pada pengguna jasa JNE di Yogyakarta, dan Citra Merek berpengaruh positif dan signifikan terhadap loyalitas pelanggan melalui kepuasan pelanggan pada pengguna jasa JNE di Yogyakarta.

Implikasi

\section{Implikasi Teoritis}

Berdasarkan analisis dan hasil penelitian yang telah dilakukan menunjukkan bahwa variabel kualitas layanan dan citra merek berpengaruh positif dan signifikan terhadap kepuasan pelanggan, kualitas layanan, citra merek merek dan kepuasan pelanggan berpengaruh positif dan signifikan terhadap loyalitas pelanggan pelanggan, serta kualitas layanan dan citra merek berpengaruh positif dan signifikan terhadap loyalitas pelanggan melalui kepuasan pelanggan. Hasil penelitian pada variabel citra merek terhadap loyalitas pelanggan berbeda dengan hasil penelitian sebelumnya Dimyati \& Subagio (2016) membuktikan bahwa citra merek berpengaruh positif dan tidak signifikan terhadap loyalitas pelanggan. Hasil ini mengartikan bahwa model penelitian yang dikembangkan oleh peneliti sebelumnya belum konsisten. Perbedaan karakteristik responden bisa menjadi salah satu faktor yang menyebabkan perbedaan pada hasil penelitian ini. Diharapkan penelitian ini dapat menjadi referensi bagi peneliti selanjutnya khusunya untuk meneliti pengaruh kualitas layanan dan citra merek terhadap loyalitas pelanggan melalui kepuasan pelanggan.

\section{Implikasi Manajerial}

Berdasarkan hasil penelitian ini memberikan sejumlah implikasi manajerial bagi perusahaan jasa JNE sebagai berikut :

Berdasarakan hasil analisis, pada variabel kualitas layanan indikator dengan rata-rata terendah adalah ruang pelayanan luas dengan nilai rata-rata 3.97. Maka bagi perusahaan untuk memperhatikan kebersihan dam menambah fasilitas dalam ruangan agar pelanggan merasa nyaman dan mampu menarik kembali pelanggan untuk datang mengunakan jasa JNE lagi.

Berdasarakan hasil analisis, pada variabel kepuasan pelanggan indikator dengan rata-rata terendah adalah kenyamanan parkir dengan nilai rata-rata 3.96. Maka bagi perusahaan untuk meningkatkan pelayanan parkirnya dari segi luas, rapi dan bersih agar pelanggan merasa nyaman dan puas. Pada hasil penelitian analisis inner model (Gambar 4.2) ditunjukkan pengaruh yang paling terkecil ditunjukkan oleh pengaruh kualitas layanan terhadap loyalitas pelanggan yaitu sebesar 2.346. Maka bagi perusahaan untuk meningkatkan dan memberikan kualitas layanan JNE lebih baik lagi. Dengan memberikan pelayanan yang memuaskan dan menganggap pelanggan sebagai mitra, maka pelanggan akan semakin loyal dan menggunakan jasa JNE terus menerus. Demikian tujuan perusahaan akan mudah dicapai terutama untuk meningkatkan profitabilitas dan memenangkan persaingan.

\section{DAFTAR PUSTAKA}

[1] Dimayati, Mohamad, and N. Ari Subagio. 2016. "Impact of Service Quality, Price , and Brand on Loyalty with the Mediation of Customer Satisfaction on Pos Ekspres in East Java Mohamad Dimyati." 7(4):74-86. doi: 10.5901/mjss.2016.v7n4p.

[2] Gerson, Richard F. 2004. Mengukur Kepuasan Pelanggan. Jakarta: PPM.

[3] Ghozali, Imam, and Hengki Latan. 2015. Konsep, Teknik, Aplikasi Menggunakan Smart PLS 3.0 Untuk Penelitian Empiris. Semarang: BP Universitas Diponegoro.

[4] Keller, Kevin Lane Ambi M. G. Parameswara \&. Isaac Jacob. 2015. Strategic Brand Management: Building, Measuring, and Managing Brand Equity. Fourth. India: Pearson Education Services Pvt. Ltd.

[5] Kotler, Philip \&. Gary Amstrong. 2001. Prinsip-Prinsip Pemasaran. Kedelapan. Jakarta: Erlangga.

[6] Kotler, Philip, and Kevin Lane Keller. 2016. Marketing Mangement.

[7] Lupiyodi Rambat. 2001. Manajemen Pemasaran Jasa Teori Dan Praktik. Pertama. Jakarta: Salemba Empat. 
[8] Lupiyodi Rambat. 2018. Manajemen Pemasaran Jasa: Berbasis Kopetensi. Ketiga. Jakarta: Salemba Empat.

[9] Nastiti, Aridara, and Sri Rahayu Tri Astuti. 2019. "TERHADAP LOYALITAS PELANGGAN TAKSI NEW ATLAS DI KOTA Aridara Nastiti , Sri Rahayu Tri Astuti." Diponegoro Journal of Management 8(1):126-36.

[10] Sutisno SE. ME. 2001. Perilaku Konsumen Dan Komunikasi Bisnis. Bandung: PT Remaja Rosdakarya.

[11] Syahputra, Dwi Arry. 2020. "Pengaruh Kualitas Layanan Dan Citra Merek Terhadap Loyalitas Melalui Kepuasan Nasabah Perum Pegadaian Cabang Bekasi Timur." 21(2):80-92.

[12] Tiasanty, Lise, and Arifin Sitio. 2019. "Analysis of the Effect of Service Quality, Product Quality and Brand Image on Customer Satisfaction and Its Implications on Consumer Loyalty Pt. Sharp Electronics Indonesia (Case Study At Karawang Sharp Direct Service Station)." International Journal of Engineering Technologies and Management Research 6(6):197-212. doi: 10.29121/ijetmr.v6.i6.2019.408.

[13] Tjiptono, Fandy. 2018. Manajemen Jasa. Yogyakarta: Andi Offset.
Service Quality,

Brand Image and

Customer Loyalty to

Jne Customers

307 